\title{
La historia de las palabras relacionadas con la anatomía del aparato genital femenino
}

\author{
Miguel Angel Alarcón Nivia, MD ${ }^{1}$
}

\begin{abstract}
RESUMEN: Se hace mención a la historia de las principales palabras que describen la anatomía del aparato genital femenino buscando su nacimiento en la mitología, en la historia de la medicina, en la filología y en las raíces etimológicas del latín, el griego y lenguas afines.

PALABRAS CLAVES: Anatomía genital, Etimología, Historia de las palabras, Historia de la Ginecología.

SUMMARY: This paper talks about the history of the words used in the female genital tract. You can know the origin of some terms and the way the mithology, the latin, greek and similar languages have contributed to rich the vocabulary in anatomy.
\end{abstract}

KEY WORDS: Genital anatomy, Etimology, History of words, History of Ginecology.

\section{Introducción}

Este artículo es una mirada al legado etimológico de los forjadores de la historia que con su paciente labor empezaron a iluminar el tortuoso camino de la anatomía, que tantos siglos después, aún nos guarda secretos.

Vulva (Nombre oficial: Vulva) Latín: Pudendus, Vulva, Cunnus. Griego: Episio. Sinónimo: Pudendo femenino.

Dos formas de mencionar la vulva en latín son Pudendum muliere y Feminae pudenda. (1-2, 39).

La raíz Pudendus tiene dos orígenes:

a- Pudendum: deshonroso, que causa vergüenza

b- Pudoris: timidez, vergüenza.

Pudicia: Diosa de la mitología griega que personificaba la virtud. Su estatua era adorada en un altar del templo de la fortuna representando la castidad femenina y la fidelidad conyugal. Hay una escultura en el museo Vaticano de la diosa Pudicia, con velo y ropajes que cubren todo su cuerpo.

Las palabras Vulva y Volva significan al mismo tiempo Vulva y Matriz. Se desconoce la razón por la cual se emplea el mismo término en latín para dos órganos tan diferentes.

Cunnus: Vulva, Periné femenino, genitales externos. Esta palabra es usada principalmente por los sexólogos al referirse al Cunnilingus: estimulación lingual de la vulva durante la relación sexual (50).
Ginecólogo-Obstetra. Profesor del Departamento de Gineco-Obstetricia Universidad Industrial de Santander. Fellow de Epidemiología Clínica, Pontificia Universidad Javeriana.
Episio, raíz griega utilizada por ejemplo para la palabra Episiotomía (46), viene de las raíces Epision y Episeion que hacen referencia al pubis. Otro origen probable es la raíz Episeyo que significa excitarse y que haría mención a este órgano como centro erógeno (33).

Labios mayores de la vulva: (Labium majus pudendi) $(1,39)$ Latín: Labium, Labrum

Estas estructuras fueron llamadas Labios por primera vez cuando Colombo de Cremona acuñó este término en la primera mitad del siglo XVI (44). Su forma y ubicación a la entrada de una cavidad los hace comparables a los labios de la boca.

La palabra Labio viene del latín Labium y este del latín antiguo Labrum. Hasta el siglo XVI se mencionaban estos órganos en España y América como Labrios o Labros $(4,14)$.

El Dr. Desmond Morris hace la comparación entre los labios de la boca y de los genitales de la siguiente forma: "Una manera de transmitir señales genitales visuales consiste en emplear alguna parte del cuerpo como imitación o eco genital". Esto permite enviar mensajes manteniendo ocultos los verdaderos órganos....Igual que los labios de la boca, los labios genitales rodean un orificio central y de manera similar se enrojecen e hinchan con el estímulo sexual. Desde los primeros tiempos históricos, la mujer acentuó sus señales labiales con la aplicación de un color artificial. El lápiz de labios es actualmente uno de los productos cosméticos más importantes y aunque los colores varían con la moda, siempre vuelven al rojo vivo, copiando el enrojecimiento labial en los estados avanzados de excitación. Desde luego no se trata de una imitación consciente de las señales sexuales sino de algo puramente sexy y atractivo sin más complicaciones...También se ha pretendido que la estructura de los labios de una mujer determinada, refleja la estructura de sus genitales ocultos. Así, se presume que la mujer de labios carnosos posee un órgano genital carnoso y que la 
de labios finos y apretados tiene un órgano genital fino y estrecho. Si esto es realmente así, refleja un tipo somático de la mujer en cuestión." $(42,49)$.

\section{Horquilla (Frenulum labiorum pudendi) $(1,39)$.}

Sinónimo: Frenillo de los labios del pudendo. El término frenillo significa: repliegue membranoso que limita los movimientos de una estructura.

Angulo inferior de la vulva donde se unen los labios mayores para iniciar el periné ginecológico. La unión de los labios mayores y el pliegue central del periné forman una letra "Y", que es la forma de una horqueta (3).

Horquilla es una horca pequeña u horqueta. Horca se originó del latín Furca, palo bifurcado que se utilizaba para amarrar y conducir los esclavos por la calle para exponerlos al escarnio público cuando habían cometido una falta. Si se le adicionaba otro palo atravesado servía para ahorcar a los condenados, práctica muy frecuente en el medioevo $(2,14)$.

\section{Labios menores de la vulva}

(Labium minus pudendi). También llamados Ninfas $(1,2,3,39)$

Las ninfas en la mitología griega eran diosas jóvenes de menor rango

El término ninfas dio origen a la palabra ninfomanía: hipersexualidad femenina $(2,46)$. Segatore en 1971 le daba los sinónimos de metromanía y furor uterino y la definía como violento desequilibrio interhormonal y alteración psico sexual. (22)

Las ninfas debían preservar la naturaleza. Por esto se les conoce de acuerdo a su oficio: Oceánidas, las que cuidaban el océano; Nereidas, cuidaban el Mar Mediterráneo; Leimónidas o ninfas de las praderas; Dríadas o Hamadríadas, cuidaban los árboles; Mélidas, protegían los frutales; Oréadas u Orestíadas, cuidaban las montañas y las grutas y acompañaban a la diosa Diana la Cazadora (Artemis); Naíadas, ninfas de las fuentes; Potámidas, cuidaban los ríos; Limníadas, protectoras de los lagos.

Tal vez la escultura más conocida de estas diosas es "Apolo asistido por las ninfas" de Francois Girardon, en el palacio de Versalles (19).

\section{Clítoris (Clítoris) Griego Kleitorís (1-2, 39,46).}

El clítoris representa el pene masculino (50) por lo cual se le ha dado el nombre latino de Membrum muliebre o Coles foeminarum.

La raíz griega más probable que da origen a esta palabra es Kleitorís, utilizada también para bautizar dos plantas venenosas de Panamá y Brasil: la Clitoria arborescens y la Clitoria glycinoides.

Kleitorís viene de Kleieia: cerrar, pero existe la posibilidad de que se origine de Klitós: inclinado, por la posición permanente de este órgano.

(Estaría pensando Gabriello Fallopio en la raíz griega Klytós: "famoso", cuando bautizó este órgano en el siglo XVI?).

Clítoris: Diosa de la mitología griega, tan extraordinariamente hermosa y diminuta que Júpiter (Zeus) tuvo que transformarse en hormiga para conseguir su amor (33).

\section{Bulbos Vestibulares (Bulbus vestibuli).}

Organos eréctiles homólogos del cuerpo esponjoso masculino, reciben el nombre de bulbos por tener forma abultada y redondeada. El nombre de vestibulares se debe a su ubicación a lado y lado de los vestíbulos uretral y vaginal. $(1,3,39,50)$.

\section{Glándulas Vulvo-Vestibulares o glándulas de Bartholin}

(Glandulae vestibularis major) $(1,39)$

Descritas por el Dr Caspar Berthelsen Bartholin (llamado en latín Gaspard Bartholinus).

Caspar B. Bartholin: médico y teólogo nacido en Malmo, Dinamarca en 1585, murió en Zoro, Zelandia a la edad de 44 años. Fue profesor de anatomía de la Universidad de Copenhage y luego en la Universidad de Padua donde trabajó con el famoso profesor italiano Hieronymus Fabricius Aquapendente.

Hizo dos aportes importantes a la anatomía: fue el primero en describir el bulbo olfatorio como nervio craneal responsable del olfato y el primero en describir las glándulas lubricantes vestibulares que llevan su nombre. Escribió el libro "Anatomicae Institutiones Corpori Humani”, uno de los libros más leídos del renacimiento traducido a varios idiomas. Al final de su carrera se dedicó a la cátedra de la divinidad en la Universidad de Copenhage. Tuvo dos hijos, ambos brillantes médicos y profesores de la misma universidad: Thomas B., pionero en la descripción de todo el sistema linfático y Erasmus B., quien describió el fenómeno de la doble refracción de la luz al pasar por un cristal. (2)

Pubis y Monte de Venus (Os pubis y Mons pubis) (1, 39)

Pubis: tomado del latín tardío Pubis que a su vez se derivó del latín clásico Pubes: vello masculino, bajo vientre, la parte privada. Blanquez opina que a su vez Pubes se originó del griego Phoibe: pelo rizado, signo de pubertad, joven en estado de llevar las armas. El primer registro de la palabra Pubis aparece en 1817.

Monte de Venus: Región superior del perineo por delante del hueso pubis, cubierta de vello desde la pubertad. (46)

Venus es el nombre romano de Afrodita, diosa griega de la belleza y del amor.

Venus, hija de Urano (el cielo) y de Gea (la tierra), esposa de Vulcano (o Hefestos), amante de los dioses Ares, Dionicio, Hermes y Poseidón y de los mortales Anquises y Adonis. Sus hijos más conocidos son Cupido (Eros), Anteros, Himen y Hermafroditus. Esta diosa había provenido inicialmente de Fenicia y se le adoraba en múltiples países de Europa, Asia y el norte de Africa por lo cual se le conocía con unos 100 nombres (ref. 34, edición 1922 p. 1314) que mencionan su poder sobre la tierra, los cielos, la fecundidad, la vida, la muerte, el amor, la belleza y aún de la prostitución. Los nombres más frecuentes eran Astarté, Venus Victrix, Venus Genitrix, Venus Myrtea y Venus Ericina.. Entre las plantas consagradas en su honor estaban 
el mirto, la rosa y la manzana. Se dedicaba la paloma en su honor por ser un ave prolífica y se le sacrificaba dicho animal como principal ofrenda. Entre los israelitas se llegó a ofrendarle sacrificios de niños (34)

En su honor se bautizaron el día viernes y al planeta Venus por ser considerada la diosa de este cuerpo celeste (34). Las enfermedades venéreas (enfermedades del amor) tomaron su nombre en Roma de esta diosa que había llegado de Grecia. Por ser una divinidad venida de afuera la Afrodita griega se conocía en Roma con el nombre popular de Venere (ref 34 edición 1922 p. 1315)

Los artistas han rendido homenaje a esta diosa a través de la historia de la pintura y la escultura. Son particularmente famosas las dos pinturas sobre el nacimiento de Venus, "La nascita di Venere" de Sandro Boticelli (galería degli Uffizi, Florencia) y "La naissance de Vénus" de Alexandre Cabanel ( musée d’Orsay, Paris). Hay muchas versiones sobre el juicio de Paris (19), donde se la representa recibiendo la manzana por su belleza. Entre las esculturas sobresalen La Venus de Willendorf, estatuilla de piedra caliza elaborada unos 25 siglos a.J.C, representante de la fertilidad (52); La Venus de Milo (museo de Louvre, Paris), escultura sin brazos encontrada en la isla griega de Milo, en el mar Egeo, al parecer esculpida por Scopas en el siglo IV. $(14,19)$ y la Venus de Praxiteles de la cual hay copias en Munich y El Vaticano (19).

\section{Glándulas de Skene o Glándulas Periuretrales}

(Glandulae urethrales) (1,39). Descritas en 1880 por el Dr. A.J.C. Skene.

\begin{abstract}
Alexander Johnson Chalmers Skene, médico escocés-norteamericano, uno de los pioneros de la Ginecología en los Estados Unidos en la segunda mitad del siglo XIX. Nació en Aberdeen, Escocia en 1838 y murió en Nueva York a los 62 años de edad. Llegó a los 19 años a Míchigan y allí logró el título de médico. Se vinculó como profesor de ginecología del hospital de Long Island y como consultor de varios hospitales por lo cual fue uno de los ginecólogos más reconocidos de la época. Describió las glándulas que llevan su nombre (The anatomy and pathology of two important glands in the female urethra. Am. J. Obstet. Dis. Women Child, 1880). Escribió varios textos y tratados de medicina. $(1,39,46)$
\end{abstract}

Himen (Hymen, hymenis) $(1,39,131)$

La primera descripción del himen fue hecha por Gabriello Fallopio en el siglo XVI (44) aunque no se sabe quien acuñó su nombre.

La mayoría de autores que indagan el origen de esta palabra lo atribuyen al latín Hymen, Hymenis, Hymenaeus: matrimonio, poema nupcial que se hacía a los recién desposados o canto que se ofrecía en su honor durante la boda.

Himenaeus o himeneo: Canto nupcial, apareamiento de los animales.

Refieren Blanquez ( 7) y Segatore (22) que la palabra himen viene del griego Imen, Imenos: membrana y que de allí se derivaron las palabras en latín.

Hymen: Diosa del matrimonio en la mitología griega. Hija de Venus y Dionicio. En otra leyenda griega Hymen era un joven dios que rescató a un grupo de mujeres, incluida la que él amaba, de una banda de piratas ; como premio pudo casarse con ella. Este episodio fue recordado después en las canciones (himeneos) dedicadas al matrimonio (33).

\section{Carúnculas Mirtiformes (Carunculae hymenales) $(1,39)$}

Carúnculas mirtiformes: carnosidades o flecos en que se convierte el himen luego de múltiples coitos o de un parto (46).

Carúncula: diminutivo de caro, carne. Pedazo pequeño de carne. Carnosidad que sobresale en algunas partes del cuerpo (22).

Mirtiforme: en forma de mirto (latín myrtus y este del griego myrtos). Mirto es sinónimo de arrayán.

La comparación de las carúnculas himeneales con las hojas del mirto (46) no es mera casualidad; este arbusto tenía gran importancia en los territorios del Imperio Romano. En la época de Rómulo se adoraba a la Venus Myrtea en el bosque de los mirtos, en el valle formado por los montes Aventino y Palatino, donde después se construyó el circo romano. Los sabinos y los romanos se purificaban con esta planta, símbolo del amor y de la unión de las parejas $(24,34,37-38)$.

\section{Vestíbulo (Vestibulum vaginae)}

Conducto vulvar o espacio que está antes de la entrada a la vagina $(1,3,39,46)$.

Vestíbulo: Atrio o portal que está a la entrada de una casa o edificio. La palabra vestíbulo se originó del honor que se le hacía a la entrada de las casa y de los edificios a la diosa Vesta (Cibeles), diosa de los hogares (14).

Las vestales eran unas vírgenes en Roma, con figura religiosa, cuya función era venerar a la diosa Vesta y guardar y preservar el fuego perpetuo donde se le hacían sacrificios. Si por desgracia el fuego se apagaba era motivo de gran escándalo por lo cual eran castigadas severamente. Solo se podía reponer mediante el fuego producido utilizando los rayos del sol. Las vestales ingresaban al servicio desde los 16 años y debían permanecer en el mismo durante 30 años. Si durante ese lapso tenían relaciones sexuales eran enterradas vivas. El culto a la diosa Vesta fue instituido por Numa Pompilio $(14,33)$.

Fosa o fosita navicular (Fossa vestibuli vaginae) $(1,39)$

Fosa del vestíbulo vaginal. Lugar más profundo en forma de surco del conducto vulvar que forma el piso del vestíbulo vaginal $(3,46)$

Navicular viene del latín Navicula: Semejante a una nave o barco; barquita o barquichuela (7)

\section{Vagina (Vagina) $(1,14,39)$ Latín vagina, griego Kolpos.}

Vagina: Vaina, estuche, envoltura. La palabra vagina fue utilizada por primera vez por Colombo de Cremona (1516-1559), quien además describió las rugosidades de su mucosa y fue el primero en publicar un caso congénito de ausencia de útero y vagina $(41,44)$, entidad que a partir del siglo XIX sería estudiada por Mayer, Rokitanski, Kuster y Hauser. Algunos historiadores dan la paternidad 
de la palabra vagina a Fallopio, quien era contemporáneo de Colombo.

En la península ibérica se la mencionaba como vaína hasta 1817 cuando la academia la reemplazó por vagina. Colpos viene del griego Kolpos: cavidad. $(7,14,46)$.

El triángulo de Pawlik, bifurcación del tubérculo vaginal en la cara anterior de la vagina, fue mencionado por primera vez por Karel J. Pawlik, ginecólogo de Praga (1849-1914).

La fascia de Halban, que separa la vejiga de la vagina, fue descrita por Joseph Halban, ginecólogo de Austria (1870-1937), contemporáneo de Pawlick (2).

\section{Punto de Grafenberg o Punto G o Zona G}

Es una pequeña zona erógena ubicada en la cara anterior de la vagina, a nivel de la unión uretrovesical (18). El primer investigador en resaltar la importancia de esta zona fue el ginecólogo y obstetra alemán Ernst Grafenberg. Se llama punto o zona de Grafenberg desde que los sexólogos Perry y Whiple lo bautizaron con este nombre en el Foro Internacional de Relaciones Humanas en 1981 (17-18).

En el año 1944 el Dr. Grafenberg, en colaboración con el Dr. Robert L. Dickinson (considerado como el primer sexólogo norteamericano) describieron "una zona de sensación erótica que está ubicada a lo largo de la superficie suburetral de la pared anterior de la vagina, a medio camino entre la parte posterior del hueso pubis y la cara anterior del cuello del útero, donde la vejiga se une a la uretra." Seis años más tarde escribiría Grafenberg: “...durante el estímulo sexual la uretra femenina empieza a dilatarse y puede percibirse fácilmente.". Hallazgo similar hizo el médico israelita Zwi Hog quien afirmaba en 1980 "la excitación percibida en la pared anterior de la vagina es diferente a la del clítoris, aunque en algunas mujeres el estímulo de aquella zona puede ser más eficaz" (Hog Z.The sensory of the female orgasmic reflex. Journal of sex education and therapy, 1980 p. 4-7). La Dra Alice Ladas, escribe que esta zona es óptimamente estimulada digitalmente por el compañero sexual cuando la mujer toma la posición genupectoral (2) o la posición de cuadrúpedo durante el coito (18). Los Drs. Masters y Johnson hacen alusión a esta región de la vagina que se expande en la fase excitatoria y se congestiona durante la fase orgásmica como consecuencia de la intensa vasodilatación que compromete el tercio inferior de ambas caras de la vagina (plataforma orgásmica) cerrando su luz en un 50\% (43).

\section{Fornix o Fondo de Saco Vaginal. (Fornix} vaginae) $(1,39)$

La palabra Fornix es de origen incierto pero hace referencia a la forma de bóveda que tiene cada uno de los fondos de saco de la vagina alrededor del cuello.

Las entradas en forma de arco y bóveda de las murallas de las ciudades y de los edificios públicos (como el Circo Romano), dieron origen a la palabra Fornicar como acto de tener relaciones en los fórnices con las mujeres que allí acudían, a quienes se les llamaba fornicarias.

Así lo expresa Covarruvias en castellano antiguo: "Fornicar: en rigor tener acceso con muger pública que tiene su casilla señalada y porque antígua mente eran unas hornachuelas pegadas al muro de la ciudad por fuera della. De la palabra fornix se dixeron fornicarias tales mugeres y el tener cuenta con ellas fornicar. No obstante cualquier ayunta miento que el hombre tenga con otra muger que la propia y legítima se llama fornicio" (14).

Fornix: Bóveda, recinto abovedado, lupanar, lugar de prostitución.

Fornicar: Tener trato sexual con prostitutas o con persona con la que no se ha casado $(24,33)$.

Fondo de Saco de Douglas (Excavatio rectouterina) $(1,39)$

Sinónimos: Fondo de saco recto-uterino, pliegue recto-uterino.

Esta estructura es mencionada en francés y a veces en inglés como Cul-de-sac $(45,47)$ que no tiene equivalente en español. Sin embargo, la palabra culdocentesis que sí existe en nuestro idioma, es una centesis (punción) del cul-de-sac (39) .

James Douglas, anatomista de Londres (1675-1742) hizo conocer la importancia de la punción de este saco para drenar abscesos de la cavidad peritoneal y como procedimiento diagnóstico (46).

\section{Tabique Recto-Vaginal (Septum recto-vaginale)}

Es la pared que separa la vagina del recto. La palabra Tabique viene del árabe Taxbic: pared de ladrillo. $(1,5,39)$

\section{Cuello (Cervix uteri) $(1,39)$}

Latín Cervix, Griego Traquelo. Sinónimos: Ocico de tenca, cervix.

Cuello viene del latín Collum. El término cérvix es sinónimo de cuello uterino; Traquelo se refiere al cuello de la cabeza, al cuello de la vejiga y al cérvix. En este caso se usa para referirse al traquelocele y a la traquelectomía. Tráquelo es la forma prefija del griego Tráchelos: cuello, pescuezo, nuca.

El nombre de ocico de Tenca con que se bautizó en la antigüedad a la parte visible de este órgano (la portio vaginalis) significa boca de Tenca por su enorme parecido con la boca redonda e hinchada de la Tenca tinca, pez teleósteo de la familia de los ciprínidos. Se encuentra en los mares de Europa y Asia occidental. Mide unos $50 \mathrm{~cm}$ (6-7, 21, 32-33).

\section{Utero (Uterus) $(1,14,39)$}

Latín uterus, Griego: Metra, histera. Sinónimo: Matriz, vientre $(2,14,33)$

Mondino de Luzzi fue autorizado para iniciar la disección de cadáveres en el año 1315 en la Universidad de Bolonia, Italia. Este acontecimiento marcó el final del oscurantismo en el conocimiento de la anatomía humana (44), mantenido por la prohibición de la iglesia católica de hacer autopsias (41). Las disecciones de Mondino permitieron desechar la creencia de que el útero podía caminar sin rumbo por el cuerpo, pero aceptó el concepto de que la sangre menstrual retenida durante el embarazo salía por los senos en forma de leche (44). 
Berengario de Carpi demostró en el siglo XVI que el útero tenía una sola cavidad y no siete como se creía hasta entonces, concepto que había sido postulado por Galeno de Pérgamo en el siglo II quien suponía que los embriones masculinos se desarrollaban en las cavidades derechas, los embriones femeninos en las izquierdas y los hermafroditas en el centro.

Las disecciones de cadáveres de Andreas Vesalio, ( anatomista y cirujano flamenco de la Universidad de Padua $(48,51)$ en la segunda mitad del siglo XVI, médico de la corte del rey Carlos V y luego de Felipe II), mejoraron el conocimiento de los ligamentos, uterinos. Describió la capa decidual y utilizó por primera vez la palabra útero para referirse a este órgano. Escribió sus hallazgos en el libro De humani Corporis Fabrica, $1543(44,51)$

La raíz griega Metra, matriz (2) (se utiliza para palabras como histerómetro.

La raíz histera viene del griego Hystera: matriz, (2) que también dio origen a la palabra histeria, introducida en la medicina antigua por Sorano de Efeso (siglo II) en su libro "De arte obstétrica morbisque mulierum", (considerada fundamental durante siglos) (51) por la creencia de que esta afección se originaba en la represión e insatisfacción de los estímulos eróticos de la mujer. Similar concepción tuvo Freud al considerar que la histeria era una explosión fatal en el plano psíquico de una sexualidad reprimida por los preceptos morales (22).

Ya se mencionó atrás que en latín la palabra vulva significa al mismo tiempo vulva y matriz, siendo dos órganos tan diferentes.

Los ligamentos cervicales laterales (que hacen parte de los parametrios) fueron descritos por el ginecólogo alemán Karl M. Mackenrodt (1859-1925) ( 2,46)

\section{Trompa Uterina (Tuba uterina)}

\section{Latín tuba, Griego Salpinx.}

Sinónimos: Tuba, Trompa de Fallopio. Oviducto. $(1,39)$

La palabra Trompa llegó a la península ibérica proveniente del francés Trompe. Al francés había llegado de otro idioma no definido, probablemente del alemán o de otra lengua eslava. Al inglés también llegó como galicismo $(23,45)$.

Tuba viene del latín Tubus: caño, conducto $(4,7,45)$. Salpinx viene del latín y significa trompeta.

Trompa de Fallopio hace referencia al Dr. Gabriello Fallopio, sacerdote, filólogo, naturalista y médico (51) nacido en Módena, Italia en 1523 y muerto en Padua a los 39 años de edad. Alumno de Vesalio (51), fue el anatomista más famoso del siglo XVI. Primero fue sacerdote de la catedral de Módena; luego estudió medicina en la Universidad de Ferrara donde obtuvo el cargo de profesor de anatomía. Posteriormente profesor de anatomía, cirugía y materia médica en las universidades de Pisa y Paduà. Describió los canales semicirculares del oído interno y le dio el nombre a la vagina, placenta, clítoris, paladar y cóclea. "Redescubrió" las trompas uterinas en 1561, que habían sido descritas por Herófilo de Calcedonia en el siglo IV antes de Cristo, como "canales de la matriz" pero sin adjudicarles alguna función $(37,41,44)$. En el siglo II Galeno había demostrado que las trompas entraban al útero y no a la vejiga como se creyó hasta entonces. (44,51).

Fallopio escribió sus estudios en el libro "Observationes Anatomicae" (1561) que valió la admiración de su profesor y colega Andreas Vesalio (44). Juntos contribuyeron en forma importante al desarrollo de la anatomía durante el renacimiento.

El término Oviducto fue empleado por primera vez por De Graaf (44).

La palabra Istmo viene del latín isthmus o isthmos, estrecho o angostura (33)

Ampolla viene del latín ampula, dilatación.

Infundíbulo viene del latín infundibulum, embudo.

Fimbria significa orlas, franjas.

Hidátide de Morgagni: Hidátide viene del latín Hydatidis que significa botón de rosa, papila y pezón (33). La primera descripción de la hidátides fue hecha por el notable profesor italiano Giovanni Batista Morgagni en el siglo XVII.

Ostium (el orificio de la trompa) viene del latin puerta, entrada, fauces. El plural de ostium es ostia. (33)

\section{Ovario (Ovarius) $(1,39)$}

Latín Ovarius, Griego Ooforos. Sinónimo: Gónadas femeninas.

Los ovarios fueron descritos por Herófilo de Calcedonia en el siglo IV antes de J.C. a los cuales les dio el nombre de "dídimos o testículos femeninos" pues consideró que su estructura era igual a la del testículo masculino. $(37,41,44)$. Se mantuvo este nombre hasta 1621 cuando Fabricio de Acquapendente le puso el nombre de Ovarios y le asignó la función de regar al útero a la manera de un jardín para que su suelo fuera fértil y el semen masculino pudiera germinar.

Gabriello Fallopio en 1561 había refutado la creencia de que el ovario contenía semen y el primero en utilizar la palabra "lúteo" en vez de "humor acuoso del ovario". (44). Galeno en el siglo II dedujo que la extirpación de los ovarios suspendía la capacidad de procrear hijos con base en sus observaciones en la ciudad de Capadocia en el Asia donde era costumbre castrar a la hembra del cerdo (41).

El médico griego de mayor importancia después de Hipócrates fue Galeno quien estudió en Alejandría y ejerció la medicina durante el resto de su vida en Roma. La ciudad de Alejandría sobre el Nilo, fundada por Alejandro el Grande en el año 332 a.C se convirtió en el centro geográfico universal de la ciencia durante los siglos III y II a.C. En un momento dado la ciudad albergaba 14.000 estudiantes de las diversas ramas de la cultura helenística almacenada en 70.000 pergaminos de la mayor biblioteca de la antigüedad. (48). La mayoría de preceptos de Galeno se mantuvieron vigentes por 10 siglos $(44,48)$.

Aunque se considera que el descubridor del folículo ovárico fue Reigner De Graaf, dada la magistral descripción del mismo en 1672, este a su vez dio como descubridor a Van Hoorne en 1662. Von Haller lo bautizó folículo 
de De Graaf en 1766, denominación que se ha conservado hasta el presente (44).

El cuerpo lúteo fue bautizado por Malpighi en 1686 pero había sido descubierto por De Degraaf años antes. Luteum significa de color amarillo, yema de huevo.

Corpus albicans significa cuerpo blanco.

El óvulo solo fue observado por primera vez por von Baer en 1827 en una perra en celo $(33,40,44)$. Dos siglos antes William Harvey había postulado: "El huevo es el origen común de todo ser vivo" (51). Ovulo viene del griego Ovum que a su vez viene del griego antiguo Oón (21).

\section{Espacio prevesical de Retzius (Spatium retropubicum) $(1,39)$}

Estrictamente hablando este espacio no tiene nada que ver con el aparato genital. Pero tiene gran importancia quirúrgica para los ginecólogos que despegan la vejiga del pubis, forman el espacio retropúbico también llamado prevesical, para llegar hasta el paracolpos durante la cistopexia de Burch o cualquiera otra de las variantes de la técnica original de Marshall Marchetti Krantz (54). Este espacio fue descrito por el Dr. Anders Adolf Retzius, anatomista sueco nacido en 1796. Murió a los 64 años. Además de este espacio describió las fibras del oído y las venas intestinales que llevan su nombre (2)

\section{Seno o mama (Mamma) $(1,33,39)$} Teta.

Latín mamma. Griego mastos (2) Sinónimos: Pecho,

Existe resistencia entre muchos ginecólogos de aceptar la palabra Seno por tener esta palabra el significado de "cavidad". Sin embargo todos los buenos diccionarios aceptan este sinónimo $(4,6,11-12,14,24,33,38,46)$.
Veamos dos ejemplos: Blanquez define Seno como sinuosidad, regazo, pecho (7). Martínez lo define como concavidad, hueco, pecho o regazo (33).

Aréola (areola mammae): Area pequeña. Diminutivo del latín area.

Pezón (Papillae mamamae): Latín mamila, griego téle. Mamila es teta pequeña (33), diminutivo del latín mamma.

La raíz griega tele, para pezón, se utiliza en las palabras politelia, telotismo, etc.

Los pequeños tubérculos de Morgagni en la aréola se hipertrofian durante el embarazo y la lactancia razón por la cual cambian de nombre a tubérculos de Montgomery.

Giovanni Battista Morgagni, anatomista italiano nacido en Forli en 1682, murió en Padua a los 89 años. Fue profesor de anatomía de la Universidad de Padua; se considera el fundador de la anatomía patológica. Escribió sus observaciones en "De sedibus et causis morborum per anatomen indagatis" (1761) que fue traducido a varios idiomas europeos $(26,52)$.

William M. Montgomery, ginecólogo de Dublín (17971859) (46).

Ligamentos suspensorios de Cooper (Ligamentum suspensoria mammae). Descritos por Sir Astley Paston Cooper, cirujano londinense en el libro Anatomy and diseases of the breast, Philadelphia, 1845. También describió los ligamentos del pubis que llevan su nombre (53), útiles en la cistopexia de Burch (54).

Conducto galactóforo (Ductus lactiferi): lactífero viene del latín Lactifer, que lleva leche (33).

La bolsa retromamaria fue descrita por el Dr. Pier Marie Chassaignac, cirujano francés del siglo XIX quien hizo aportes a la cirugía mamaria y a la traqueostomía (34).

\section{BIBLIOGRAFIA}

1. Chatain Ives. Terminología Anatómica. Edit. Norma. Cali, 1967.

2. Salvat Editores. Diccionario terminológico de Ciencias Médicas. Undécima edición. Barcelona, 1978 p.133, 204, 499, 595, 624, 704, $766,832,877,1001$

3. Bouchet Alain, Cuilleret J. Anatomía descriptiva, topográfica y funcional. Volumen dedicado al perineo. Edit. Panamericana, México, 1980 p. 306-326.

4. Corominas J. Diccionario etimológico de la lengua castellana. Edit. Gredos, Madrid 1954 Vol 1 p.1, / Vol 2 p. 919, 920, 945 / Vol 3 p.1, 2, 505, 902 / Vol. 4 p. 599, 600, 621, 665, 691, 765.

5. Eguilaz Y.L. Glosario etimológico de las palabras españolas de origen oriental. Edit. Lealtad, Santa Ana, España 1886 p: 498.

6. Gran Enciclopedia Larouse, Edit. Planeta, Barcelona Edición 1973 Vol. 5 p.3 / Vol 16 p. 7868 Edición 1993 p. 10691.

7. Blanquez F.A. Diccionario Latino-Español, Edit. Sopena, Barcelona 1954 p. 474, 809, 1085, 1249, 1296.

8. Lewis C., Short C.A. Latin dictionary Edit. Clarendon press, London 1917.

9. Espasa-Calpe Enciclopedia Universal Ilustrada, Madrid 1972; (13): 912; (14): 397; (17): .60; (48): 46.

10. The New Encyclopedia Britannica, 1992; (1): 24.

11. Diccionario de la Real Academia de la Lengua Española, Madrid 1970; (3): 635.

12. García D.U. Diccionario etimológico español e hispánico EspasaCalpe, Madrid, 1985; 1050.

13. Sandoval L. Diccionario de raíces Griegas y Latinas y de otros orígenes del idioma español. Tipografía Nacional, Guatemala 1930.
14. Cobarrubias O.S. Tesoro de la lengua Castellano-Española. Edit. Turner, Madrid 1977; p. 690, 698, 699, 746, 778, 990, 1003

15. UTHEA. Diccionario enciclopédico, México 1950; (3): 229.

16. Montaner y Simón. Diccionario enciclopédico hispano-americano de literatura, ciencias y artes $1890 ; 280$.

17-54. Grafenberg E. The role of the urethra in the female orgasm. International J. Sexol. 1950; 145-148.

18. Ladas A.K. El punto $G$ y otros descubrimientos recientes sobre la sexualidad. Edit. Grijalbo, Barcelona, 1983.

19. Salvat Mexicana de Ediciones S.A. Historia del Arte. Salvat, Barcelona.

20. Pijoan J. Suma artis. Historia general del arte. Vol IV: El arte griego, 2da edición. Edit, Espasa-Calpe, Madrid, 1945; 390.

21. Sebastián Y.F. Diccionario Griego-Español Edit. Sopena, Barcelona. Edición 1945 p.1296, Edición 1972 p. 901, 515, 545, 941 Edición 1984 p. 747.

22. Segatore L., Poli G. Diccionario médico. Edit. Teide, Barcelona Cuarta edición 1971; 230.

23. Webster's New Encyclopedic Dictionary. Edit Koneman, Cologne Germany 1993; 1115.

24. Moliner M. Diccionario del uso español. Edit Agredos, Madrid 1983; p.424, 540, 1134, 1140, 1329.

25. Diccionario enciclopédico Santillana. Edit. Elfo, Madrid 1991;(1): p. 180 / Vol 8 p. 2787.

26. The Encyclopedya Americana. American Corporation, New York 1951; (3): p. 290/Vol 10 p.734 Vol 19 p. 449, 557, 558/Vol 20 p. 526 /Vol 28 p. 8 y $9 / \mathrm{Vol} 26$ p.412. 
27. Alonso M. Enciclopedia del idioma. Edit. Aguilar, Madrid 1967; 4101.

28. Sopena. Nuevo diccionario de la lengua española. Edit Sopena, Barcelona 1929; 1124.

29. Menedez Pidal R., Gili Gaya S. Gran diccionario general de la lengua española. Edit REI Andes, Bogotá 1991; 255.

30. Masriera A.C. Diccionario de diccionarios. Edit. Montaner, Barcelona 1917.

31. Casares. Diccionario ideológico de la lengua española. Edit(?) Año(?). Libro parcialmente deteriorado en las primeras páginas, Biblioteca Nacional, Bogotá p.577.

32. Testut Jean Leo. Traité D’Anatomie Humaine, Edit. Gaston Doin, Paris Huitieme édition 1931 Tome cinquieme p.348.

33. Martínez L.P. Diccionario Latino-Español. Edit. Bouret, Paris, 1939; p.40, 139, 156, 233, 357, 409, 468, 512, 608, 766, 836, 913, 944, 945.

34. Enciclopedia Universal Ilustrada Europeo-Americana. Edit EspasaCalpe, Madrid Edición 1922 Vol LXVII p.1310-1328; Edición 1973 Vol. XVII p.60.

35. Lain Entralgo P. Historia Universal de la Medicina. Salvat, Barcelona.Vol. 6 p. 335.

36. Enciclopedia de la Mitología. Edit. Planeta Vol. 1 Barcelona 1966;140143.

37. Diccionario Enciclopédico Quillet. Edit. Aristides Quillet, Buenos Aires. 1972 Tomo IV p. 533 Tomo sexto p. 200-201.

38. Norma, Diccionario Enciclopédico Ilustrado. Edit. Norma, Barcelona. Tomo 5 1994;1477.

39. Scott J.R., DiSaia P.J. Tratado de Obstericia y Ginecología de Danforth. Edit. Interamericana, Nueva York, 1994 p. 1-18, 235, 237, 238, 1001.

40. Amaro M.S. Breve historia de la endocrinología. Edit. CientíficoTécnica, Instituto Cubano del Libro; La Habana, 1975; 157-163.
41. Sánchez Torres F. Ciencia y Reproducción humana. Edit. Universidad Nacional de Colombia, Bogotá 1991; 17-18.

42. Morris Desmond. Comportamiento íntimo. Edit. Plaza y Janes, Barcelona 1972; 40-42.

43. Masters W.H., Johnson V.E. Respuesta sexual humana. Edit. Intermédica, Buenos Aires 1978; 75.

44. Norris J.H., Hertig A.T., Abell M.R. The Uterus. Edit. Williams \& Wilkins, Baltimore 1973; (The history of uterus). p. 1-16.

45. Funk \& Wagnalls. Standard Dictionary of the english language. International edition. Edit. John Clute S.A., Mexico 1970; Vol. one p.314 Vol two p.1348,1350.

46. Diccionario Pschyrembel de Ginecología y Obstetricia. Edit. Walter de Gruyter, Berlín 1988; p. 35, 50, 65, 77, 163,183,191, 256, 282, 285.

47. Diccionario Francés-Español. Edit. Sopena, Barcelona,1983;126.

48. Bland K.I., Copeland E.M. La mama, manejo multidisciplinario de las enfermedades benignas y malignas. Edit. Panamericana, Buenos Aires 1993; 26, 31.

49. Morris Desmond. El mono desnudo. Edit. Orbis S.A., Barcelona p.47.

50. Hite Shere. El informe Hite. Estudio de la sexualidad femenina. Edit. Plaza y Janes, Bogotá 1976; 162-164.

51. Crónica de la Medicina. Edit. Plaza y Janés, Barcelona 1994; p. 24, 56, $145,179,182$.

52. Lyons A., Petrucelli J. Historia de la Medicina. Ediciones Doyma, Barcelona 1991; 24, 477.

53. Haagensen C.D. Enfermedades de la mama. Edit. W.B. Saunders Company, Philadelphia, 1971; 16.

54. Ostegard D.R., Bent A. Urogynecology and Urodynamics. Edit. Williams \& Wilkins, Baltimore 1985 